\title{
Puzzled: 100 Pieces of Autism by Nilla Childs
}

Fifth Generation Publishing, Winston-Salem, North Carolina, 2012, pp. 299, ISBN: 13:978-1469956725, $\$ 15.95$

\author{
Jordan Grapel
}

Published online: 9 August 2014

(c) Springer Science+Business Media New York 2014

It is quite fitting that the symbol used by many Autism activists is a puzzle. Treatment for children with Autism is in many ways like a puzzle. There are many pieces of information involved in treating a child with Autism, and in order for a successful outcome, all of the pieces must be used, and in the appropriate way. It can be difficult to put the pieces in the right place, but if you take the time and put in the effort, you can be quite satisfied with the result. This comparison is used as the framing device of the book Puzzled: 100 Pieces of Autism, by Nilla Childs.

Puzzled tells the true story of Nilla Childs, the mother of a boy with Asperger's Syndrome. Childs describes her relationship with her son, Daniel, and the challenges they both faced making Daniel the semi-normally functioning adult he is today. Childs illustrates this journey by compiling one hundred different stories about Daniel, and calling each story another piece of the puzzle that is Daniel. Rather than tell the story chronologically, Childs tells the story by starting with the bleakest "pieces" of Daniels puzzle, and gradually demonstrating the more hopeful "pieces." The early chapters focus on the low points of Daniels life, when he and his mother were most at odds, or he was facing the greatest challenges, and as the book progresses, the story focuses more and more on the high points of Daniel's life, when he was at his happiest and highest functioning. By telling the story in this manner, Childs not only gives the reader the full puzzle, and lets the reader know everything there is to know about her son, both the good and the bad, but she also gives the reader hope for Daniel's future.

While there are a few things that may not be correct or aren't so clearly established, the behavioral and personal aspects of this story are both accurate and heartfelt. Childs charmingly describes herself not as an expert on Asperger's syndrome, but merely as an "expert on Daniel." Not everything in this book will apply to all people with Asperger's syndrome, because as the saying goes if you've met one child with Autism you've met one child with Autism, but everyone who has a close relationship with someone on the Autism spectrum will be able to relate to some aspect of this book. Although this book is clearly geared towards parents and loved ones of person's with Asperger's Syndrome, it certainly has a little something for everyone, and experts would benefit from reading this book.

J. Grapel $(\bowtie)$

Skidmore College, 815 North Broadway, Saratoga, NY 12866,

USA

e-mail: Jordan.grapel@yale.edu 